\title{
Ferrous Campylobacter jejuni truncated hemoglobin P displays an extremely high reactivity for cyanide - a comparative study
}

\author{
Alessandro Bolli ${ }^{1}$, Chiara Ciaccio ${ }^{2,3}$, Massimo Coletta ${ }^{2,3}$, Marco Nardini ${ }^{4}$, Martino Bolognesi ${ }^{4}$, \\ Alessandra Pesce ${ }^{5}$, Michel Guertin ${ }^{6}$, Paolo Visca ${ }^{1,7}$ and Paolo Ascenzi ${ }^{1,7}$ \\ 1 Dipartimento di Biologia and Laboratorio Interdipartimentale di Microscopia Elettronica, Università 'Roma Tre', Italy \\ 2 Dipartimento di Medicina Sperimentale e Scienze Biochimiche, Università di Roma 'Tor Vergata', Italy \\ 3 Consorzio Interuniversitario di Ricerca in Chimica dei Metalli nei Sistemi Biologici, Bari, Italy \\ 4 Dipartimento di Scienze Biomolecolari e Biotecnologie and CNR-INFM, Università di Milano, Italy \\ 5 Dipartimento di Fisica, CNR-INFM, and Centro di Eccellenza per la Ricerca Biomedica, Università di Genova, Italy \\ 6 Département de Biochimie et de Microbiologie, Université Laval, Faculté des Sciences et de Génie, Québec, Canada \\ 7 Istituto Nazionale per le Malattie Infettive IRCCS 'Lazzaro Spallanzani', Roma, Italy
}

\author{
Keywords \\ Campylobacter jejuni truncated \\ hemoglobin P; cyanide binding; kinetics; \\ Mycobacterium tuberculosis truncated \\ hemoglobin $\mathrm{N}$ and $\mathrm{O}$; thermodynamics

\section{Correspondence} \\ P. Ascenzi, Dipartimento di Biologia, \\ Università 'Roma Tre', Viale G. Marconi 446, \\ I-00146 Roma, Italy \\ Fax: +39065517 6321 \\ Tel: +39065517 3200(2) \\ E-mail: ascenzi@uniroma3.it
}

(Received 7 September 2007, revised 28 November 2007, accepted 7 December 2007)

doi:10.1111/j.1742-4658.2007.06223.x
Campylobacter jejuni hosts two hemoglobins (Hbs). The Camplylobacter jejuni single-domain $\mathrm{Hb}$ (called $\mathrm{Cgb}$ ) is homologous to the globin domain of flavohemoglobin, and it has been proposed to protect the bacterium against nitrosative stress. The second $\mathrm{Hb}$ is called $\mathrm{Ctb}$ (hereafter $C j$-trHbP), belongs to truncated $\mathrm{Hb}$ group III, and has been hypothesized to be involved in $\mathrm{O}_{2}$ chemistry. Here, the kinetics and thermodynamics of cyanide binding to ferric and ferrous $C j$-trHbP $[C j$-trHbP(III) and $C j$-trHbP(II), respectively] are reported and analyzed in parallel with those of related heme proteins, with particular reference to those from Mycobacterium tuberculosis. The affinity of cyanide for $C j$-trHbP(II) is higher than that reported for any known (in)vertebrate globin by more than three orders of magnitude $\left(K=1.2 \times 10^{-6} \mathrm{M}\right)$. This can be fully attributed to the highest (ever observed for a ferrous $\mathrm{Hb}$ ) cyanide-binding association rate constant $\left(k_{\mathrm{on}}=3.3 \times 10^{3} \mathrm{M}^{-1} \cdot \mathrm{s}^{-1}\right)$, even though the binding process displays a rate-limiting step $\left(k_{\max }=9.1 \mathrm{~s}^{-1}\right) . C j$-trHbP(III) shows a very high affinity for cyanide $\left(L=5.8 \times 10^{-9} \mathrm{M}\right)$; however, cyanide association kinetics are independent of cyanide concentration, displaying a rate-limiting step $\left(l_{\max }=2.0 \times 10^{-3} \mathrm{~s}^{-1}\right)$. Values of the first-order rate constant for cyanide dissociation from $C j$-trHbP(II)-cyanide and $C j$-trHbP(III)-cyanide $\left(k_{\text {off }}=\right.$ $5.0 \times 10^{-3} \mathrm{~s}^{-1}$ and $l_{\text {off }} \geq 1 \times 10^{-4} \mathrm{~s}^{-1}$, respectively) are similar to those reported for (in)vertebrate globins. The very high affinity of cyanide for $C j$-trHbP(II), reminiscent of that of horseradish peroxidase(II), suggests that this globin may participate in cyanide detoxification.
Over the last decade, three types of hemoglobins (Hbs) have been identified in microorganisms. The first type comprises flavohemoglobins (flavoHbs), which are characterized by the classic 3-on-3 $\alpha$-helical sandwich globin domain, hosting the heme, covalently linked to a flavin reductase domain. The second $\mathrm{Hb}$ type

\footnotetext{
Abbreviations

Cj-trHbP, Campylobacter jejuni truncated hemoglobin P; flavoHb, flavohemoglobin; Hb, hemoglobin; HbC, hemoglobin C; Hbl, hemoglobin I; $\mathrm{Mb}$, myoglobin; Mt-trHbN, Mycobacterium tuberculosis truncated hemoglobin N; Mt-trHbO, Mycobacterium tuberculosis truncated hemoglobin $\mathrm{O}$; $\mathrm{trHb}$, truncated hemoglobin.
} 
comprises single-domain globins homologous to the globin domain of flavoHbs. In contrast to flavoHbs, they are devoid of the reductase domain. The third $\mathrm{Hb}$ type comprises truncated hemoglobins (trHbs), which display a smaller globin domain and the typical 2-on-2 $\alpha$-helical sandwich fold. On the basis of phylogenetic analyses, trHbs have been divided into three groups ( $\mathrm{N}$ or I, O or II, and P or III) [1-9].

Campylobacter jejuni is the most common bacterial zoonosis and the main cause of bacterial gastroenteritis in the Western world. C. jejuni is a common colonizer of the intestinal tract of wild and domestic animals, primarily birds and cattle, where it can persist at high cell density and from which it can be transmitted to humans through the orofecal route [10-12]. C. jejuni contains two $\mathrm{Hbs}$, i.e. $\mathrm{Cgb}$ and $\mathrm{Ctb}$ (the latter named $C j$-trHbP hereafter). $\mathrm{Cgb}$, belonging to the second $\mathrm{Hb}$ type, has been proposed to protect $C$. jejuni against nitrosative stress, probably via an NO dioxygenase reaction $[13,14]$. $\mathrm{Cj}$-trHbP belongs to trHb group III, and displays an extremely high $\mathrm{O}_{2}$ affinity, making it unlikely to be an $\mathrm{O}_{2}$ carrier. On the basis of the polarity of the heme distal cavity, reminiscent of that found in cytochrome $c$ peroxidase, $C j$-trHbP has been proposed to be involved in (pseudo)enzymatic $\mathrm{O}_{2}$ chemistry [15-17].

The structure of $C j$-trHbP has been solved by X-ray crystallography [16], and the surroundings of the heme distal pocket have been characterized by resonance Raman spectroscopy [17]. $C j$-trHbP shows the typical 2-on-2 $\alpha$-helical sandwich fold, despite the partial absence of the Gly-based sequence motifs that were considered necessary for the attainment of the trHb fold. Unique structural features characterize the $\mathrm{C}-\mathrm{E}$ region and the $\mathrm{FG}$ helical hinge, indicating that the heme group is more deeply buried in the protein moiety than in other Hbs. In ferric $C j$-trHbP $[C j-$ trHbP(III)], the heme-bound cyanide is stabilized by direct hydrogen bonding to TyrB10 and TrpG8. The HisE7 residue, which is about $4.5 \AA$ from the ligand, has been observed in two conformations that have been defined as open and closed. Although the gating role of HisE7 in the modulation of ligand access into and out of the heme pocket is openly debated [16,17], this mechanism is in keeping with the absence of a protein matrix tunnel/cavity system in $C j$-trHbP, in contrast to what has been observed for group I trHbs $[16,18]$. The very high affinity of $\mathrm{O}_{2}$ for $C j$-trHbP(II) has been attributed to the proposed network of hydrogen bonds that would stabilize the heme-bound $\mathrm{O}_{2}$ through residues TyrB10 and TrpG8, resulting in a very low ligand dissociation rate [17].

Being a normal inhabitant of the intestinal tract of bovines and birds [10-12], C. jejuni is likely to require cyanide detoxification system(s) when transiently exposed to breakdown products of cyanogenic glucosides ingested with the animal diet [19]. Here, the kinetics and thermodynamics of cyanide (the term cyanide refers to all forms of $\mathrm{KCN} / \mathrm{HCN}$ present in the buffered aqueous solution [20]) binding to ferric and ferrous $C j$-trHbP $[C j$-trHbP(III) and $C j$-trHbP(II), respectively] are reported and analyzed in parallel with those of related heme proteins, with particular reference to trHbs from Mycobacterium tuberculosis (i.e. $M t$-trHbN and $M t$-trHbO).

\section{Results}

\section{Cyanide binding to Mt-trHbN(III), Mt-trHbO(III), and $C j$-trHbP(III)}

Over the whole cyanide concentration range explored (from $1.0 \times 10^{-6} \mathrm{M}$ to $1.0 \times 10^{-3} \mathrm{M}$ ), the time course for cyanide binding to $M t$-trHbN(III), $M t$ - $\operatorname{trHbO}(\mathrm{III})$ and $C j$-trHbP(III) corresponds to a single exponential for more than $90 \%$ of its course between $350 \mathrm{~nm}$ and $460 \mathrm{~nm}$ (Figs 1A and 2A-C; see Eqns 1,3a,3b) [21].

Values of $l_{\mathrm{obs}}$ for cyanide binding to $M t$-trHbN(III) and $M t$-trHbO(III) are wavelength-independent but ligand concentration-dependent (Fig. 2A,B,D). The plot of $l_{\text {obs }}$ versus cyanide concentration for ligand binding to $M t$-trHbN(III) and $M t$-trHbO(III) is linear (Fig. 2D; see Eqn 2) with a $y$-intercept close to 0, indicating that $l_{\text {off }} \leq 1 \times 10^{-3} \mathrm{~s}^{-1}$; the slope of the plot of $l_{\text {obs }}$ versus cyanide concentration corresponds to $l_{\mathrm{on}}=(3.8 \pm 0.4) \times 10^{2} \mathrm{M}^{-1} \cdot \mathrm{s}^{-1}$ and $l_{\mathrm{on}}=$ $(3.2 \pm 0.3) \times 10^{2} \mathrm{M}^{-1} \cdot \mathrm{s}^{-1}$, respectively (see Scheme 1; Table 1) [18]. In contrast, values of the observed rate constant for the formation of the $C j$-trHbP(III)-cyanide species (i.e. $l_{\text {obs }}$ ) are wavelength-independent and ligand concentration-independent (Figs 1A and 2C,E). This suggests that at cyanide concentrations $\geq 1 \times 10^{-6} \mathrm{M}$, a rate-limiting conformational change(s) affects cyanide binding to $C j$-trHbP(III) $\left[l_{\text {obs }}=\right.$ $\left.l_{\max }=(2.0 \pm 0.3) \times 10^{-3} \mathrm{~s}^{-1}\right]$. According to saturation kinetics (see Scheme 2 and Eqn 4) [22], values of $L_{\text {pre }} \leq 1 \times 10^{-7} \mathrm{M}$ and $l_{\text {on }}\left(=l_{\text {max }} / L_{\text {pre }}\right) \geq 2 \times 10^{4}$ $\mathrm{M}^{-1} \cdot \mathrm{s}^{-1}$ were estimated (Table 1 ).

Cyanide binding to $M t$-trHbN(III), $M t$-trHbO(III) and $C j$-trHbP(III) follows a simple equilibrium (see Schemes 1 and 3 and Eqn 5; Fig. 3) [21,23]; values of $L$ are $(1.8 \pm 0.2) \times 10^{-6} \mathrm{M},(1.1 \pm 0.1) \times 10^{-6} \mathrm{M}$, and $(5.8 \pm 0.6) \times 10^{-9} \mathrm{M}$, respectively (Table 1). As expected for simple systems [21], values of the Hill coefficient $n$ for cyanide binding to $M t$-trHbN(III), $M t$-trHbO(III) and $C j$-trHbP(III) are $1.01 \pm 0.04$, $1.00 \pm 0.05$, and $0.99 \pm 0.04$, respectively. 

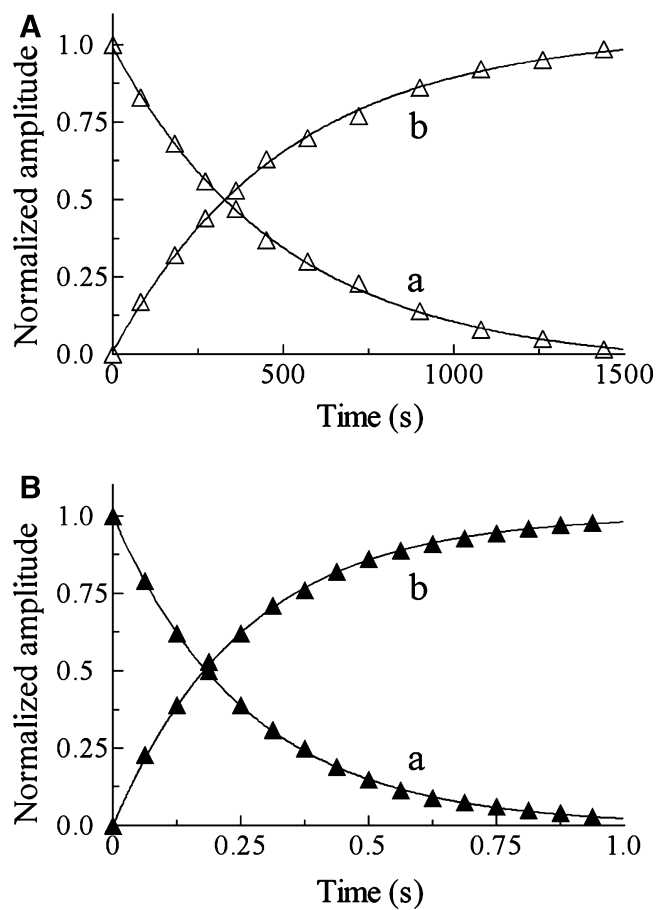

Fig. 1. Wavelength-independent kinetics of cyanide binding to $\mathrm{Cj}$ trHbP(III) and $\mathrm{Cj}$-trHbP(II). (A) Normalized time course for cyanide binding to $C_{j}$-trHbP(III) at $\lambda=410 \mathrm{~nm}$ (trace a) and $\lambda=420 \mathrm{~nm}$ (trace b). The cyanide concentration was $1.0 \times 10^{-5} \mathrm{M}$. The time course analysis according to Eqns $(3 a, 3 b)[18,21]$ yielded the following values of $I_{\text {obs }}$ : $(1.9 \pm 0.2) \times 10^{-3} \mathrm{~s}^{-1}$ (trace $\left.a, \lambda=410 \mathrm{~nm}\right)$ and $(1.8 \pm 0.2) \times 10^{-3} \mathrm{~s}^{-1}$ (trace $b, \lambda=420 \mathrm{~nm}$ ), respectively. (B) Normalized time course for cyanide binding to $\mathrm{Cj}$-trHbP(II) at $\lambda=$ $431 \mathrm{~nm}$ (trace a) and $\lambda=436 \mathrm{~nm}$ (trace b). The cyanide concentration was $1.0 \times 10^{-3} \mathrm{M}$. The time course analysis according to Eqns $(8 \mathrm{a}, 8 \mathrm{~b})[18,21]$ yielded the following values of $k_{\text {obs: }}$ : $3.8 \pm 0.4 \mathrm{~s}^{-1}$ (trace $a, \lambda=431 \mathrm{~nm}$ ) and $3.9 \pm 0.4 \mathrm{~s}^{-1}$ (trace $\mathrm{b}, \lambda=$ $436 \mathrm{~nm})$, respectively. The protein concentration was $3.5 \times 10^{-6} \mathrm{M}$. The absorbance change ranges between 0.1 and 0.3 according to $\lambda$. All data were obtained at $\mathrm{pH} 7.0$ and $20.0^{\circ} \mathrm{C}$. For details, see text.

From values of $l_{\text {on }}$ and $L$, values of $l_{\text {off }}\left(=L \times l_{\text {on }}\right)$ for cyanide dissociation from $M t$-trHbN(III)-cyanide, $M t$-trHbO(III)-cyanide and $C j$-trHbP(III)-cyanide $\left(6.8 \times 10^{-4} \mathrm{~s}^{-1}, \quad 3.5 \times 10^{-4} \mathrm{~s}^{-1}, \quad\right.$ and $\geq 1 \times 10^{-4} \mathrm{~s}^{-1}$, respectively) were estimated (Table 1).

\section{Cyanide binding to Mt-trHbN(II), Mt-trHbO(II), and $C_{j}$-trHbP(II)}

Over the whole cyanide concentration range explored (from $3.1 \times 10^{-5} \mathrm{M}$ to $1.6 \mathrm{M}$ ), the time course for cyanide binding to $M t$-trHbN(II), $M t$-trHbO(II) and $C j$ trHbP(II) conforms to a single-exponential decay for more than $95 \%$ of its course between $350 \mathrm{~nm}$ and
$500 \mathrm{~nm}$ (Figs 1B and 4A-C; see Eqns 6,8a,8b) [21]. Values of the pseudo-first-order rate constant for the formation of the $M t$-trHbN(II)-cyanide, $M t$ trHbO(II)-cyanide and $C j$-trHbP(II)-cyanide species (i.e. $k_{\mathrm{obs}}$ ) are wavelength-independent, at fixed cyanide concentration (Fig. 1B).

The plots of $k_{\text {obs }}$ versus cyanide concentration for ligand binding to $M t$-trHbN(II) and $M t$-trHbO(II) are linear (see Scheme 4 and Eqn 7) [21] (Fig. 4D) with the $y$-intercept at $(1.3 \pm 0.2) \times 10^{-2} \mathrm{~s}^{-1}$, corresponding to $k_{\text {off }}$ (Table 1). Data analysis according to Eqn (7) [21] yielded values of $k_{\text {on }}$ of $(5.0 \pm 0.6) \times 10^{-2} \mathrm{M}^{-1} \cdot \mathrm{s}^{-1}$ and $(8.5 \pm 0.9) \times 10^{-2} \mathrm{M}^{-1} \cdot \mathrm{s}^{-1}$ for cyanide binding to $\mathrm{Mt}$ trHbN(II) and $M t$-trHbO(II), respectively (Table 1). In contrast, the plot of $k_{\text {obs }}$ versus cyanide concentration for ligand binding to $C j$-trHbP(II) is hyperbolic (see Scheme 5 and Eqns 9,10) [22] (Fig. 4E) with the $y$-intercept close to 0 , indicating that $k_{\text {off }} \leq 1 \times 10^{-2} \mathrm{~s}^{-1}$. Data analysis according to Eqns $(9,10)$ [22] yielded $k_{\text {on }}=(3.3 \pm 0.4) \times 10^{3} \mathrm{M}^{-1} \cdot \mathrm{s}^{-1}, \quad K_{\text {pre }}=(2.8 \pm 0.3) \times$ $10^{-3} \mathrm{M}$, and $k_{\max }=9.1 \pm 0.8 \mathrm{~s}^{-1}$ (Table 1). The hyperbolic plot of $k_{\text {obs }}$ versus cyanide concentration indicates that conformational transition(s) compete(s) with ligand binding to $C j$-trHbP(II) at cyanide concentrations $>5 \times 10^{-4}$ M (see Eqns 9,10) [22].

Cyanide binding to $M t$-trHbN(II), $M t$-trHbO(II) and $C j$-trHbP(II) follows a simple equilibrium (see Scheme 6 and Eqn 11) [21,23] (Fig. 5); values of $K$ are $(2.4 \pm 0.3) \times 10^{-1} \mathrm{M}, \quad(1.6 \pm 0.2) \times 10^{-1} \mathrm{M}, \quad$ and $(1.2 \pm 0.2) \times 10^{-6} \mathrm{M}, \quad$ respectively (Table 1$)$. As expected for simple systems [18], values of the Hill coefficient $n$ for cyanide binding to $M t$-trHbN(II), $M t$-trHbO(II) and $C j$-trHbP(II) are $1.00 \pm 0.03$, $0.99 \pm 0.03$, and $1.02 \pm 0.03$, respectively.

From values of $k_{\text {on }}$ and $K$, the value of $k_{\text {off }}$ $\left(=K \times k_{\text {on }}\right.$ [21]) for cyanide dissociation from $C j$ trHbP(II)-cyanide $\left(4.0 \times 10^{-3} \mathrm{~s}^{-1}\right)$ was estimated.

Values of $K$ for cyanide binding to $M t$-trHbN(II), $M t$-trHbO(II) and $C j$-trHbP(II) obtained at equilibrium $\left[(2.4 \pm 0.3) \times 10^{-1} \mathrm{M},(1.6 \pm 0.2) \times 10^{-1} \mathrm{M}\right.$, and $(1.2 \pm 0.2) \times 10^{-6} \mathrm{M}$, respectively] are in excellent agreement with those calculated from kinetic parameters $\left(K=k_{\text {off }} / k_{\text {on }}=2.4 \times 10^{-1} \mathrm{M}, 1.5 \times 10^{-1} \mathrm{M}\right.$, and $1.7 \times 10^{-6} \mathrm{M}$, respectively) (Table 1). Values of $k_{\text {off }}$ for cyanide dissociation from $M t$-trHbN(II)-cyanide, $M t$ trHbO(II)-cyanide and $C j$-trHbP(II)-cyanide obtained from the kinetics and thermodynamics of cyanide binding to $\operatorname{trHb}(\mathrm{II}) \quad\left[(1.3 \pm 0.1) \times 10^{-2} \mathrm{~s}^{-1}\right.$, $(1.3 \pm 0.1) \times 10^{-2} \mathrm{~s}^{-1}$, and $4.0 \times 10^{-3} \mathrm{~s}^{-1}$, respectively] correspond to those determined by dithionite-mediated reduction of $\operatorname{trHb}(\mathrm{II})$-cyanide $\left(1.2 \times 10^{-2} \mathrm{~s}^{-1}\right.$, $1.3 \times 10^{-2} \mathrm{~s}^{-1}$, and $5.0 \times 10^{-3} \mathrm{~s}^{-1}$, respectively) $[16,18]$ (Table 1). 

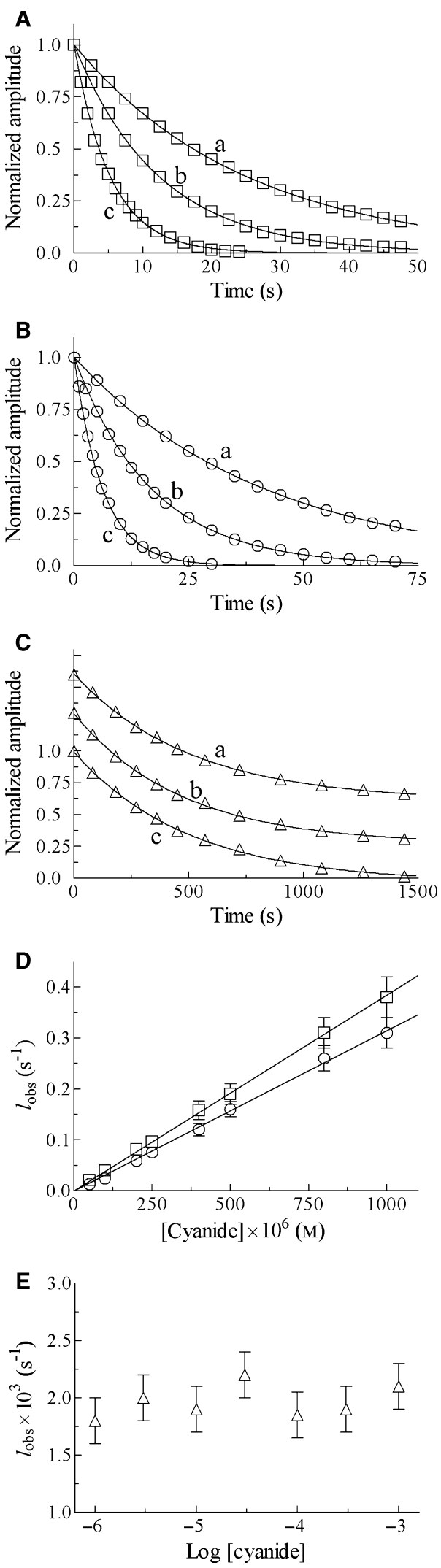

\section{Discussion}

It is well known that the heme-Fe(III)-cyanide complexes are very stable, values of the dissociation equilibrium constant being lower than $2 \times 10^{-5} \mathrm{M}$ $[18,20,21,24-30]$ (Table 1). The different stabilities of heme-Fe(III)-cyanide complexes in heme proteins are primarily determined by the rate of ligand dissociation; values of $l_{\text {off }}$ range between $3 \times 10^{-3} \mathrm{~s}^{-1}$ and $1 \times 10^{-7} \mathrm{~s}^{-1} \quad[18,20,21,25,27-32]$ (Table 1), with the exception of horseradish peroxidase and cytochrome $c$ peroxidase $\left(l_{\text {off }}=2.8 \times 10^{-1} \mathrm{~s}^{-1}\right.$ and $9.0 \times 10^{-1} \mathrm{~s}^{-1}$, respectively) $[24,26]$. Values of $l_{\text {on }}$ for cyanide binding to most heme(III) proteins range between $1 \times 10^{2} \mathrm{M}^{-1} \cdot \mathrm{s}^{-1}$ and $5 \times 10^{2} \mathrm{M}^{-1} \cdot \mathrm{s}^{-1}[18,20,21,25,27-32]$. In contrast, Glycera dibranchiata $\mathrm{HbC}$ displays an $l_{\mathrm{on}}$ value of $4.9 \times 10^{-1} \mathrm{M}^{-1} \cdot \mathrm{s}^{-1}$ [20], whereas $C j$-trHbP(III), as well as horseradish peroxidase and cytochrome $c$ peroxidase $[24,26]$ show $l_{\text {on }} \geq 2 \times 10^{4} \mathrm{M}^{-1} \cdot \mathrm{s}^{-1}$ (Table 1). However, it must be remarked that the kinetics of cyanide binding to $C j$-trHbP(III) appear to be limited by

Fig. 2. Kinetics of cyanide binding to $M t-\operatorname{trHbN}(I I I), M t-\operatorname{tr} H b O(I I I)$, and $\mathrm{C}$-trHbP(III). (A) Normalized averaged time courses for cyanide binding to $\mathrm{Mt}$-trHbN(III). The cyanide concentration was $1.0 \times 10^{-4} \mathrm{M}$ (trace a), $2.0 \times 10^{-4} \mathrm{M}$ (trace b), and $5.0 \times 10^{-4} \mathrm{M}$ (trace c). The time course analysis according to Eqn $(1)[18,21]$ yielded the following values of $I_{\text {obs }}: 4.0 \times 10^{-2} \mathrm{~s}^{-1}$ (trace a), $8.1 \times 10^{-2} \mathrm{~s}^{-1}$ (trace b), and $1.9 \times 10^{-1} \mathrm{~s}^{-1}$ (trace c). (B) Normalized averaged time courses for cyanide binding to $\mathrm{Mt}$-trHbO(III). The cyanide concentration was $1.0 \times 10^{-4} \mathrm{M}$ (trace a), $2.0 \times 10^{-4} \mathrm{M}$ (trace b), and $5.0 \times 10^{-4} \mathrm{M}$ (trace c). The time course analysis according to Eqn (1) $[18,21]$ yielded the following values of $I_{\text {obs }}: 2.4 \times 10^{-2} \mathrm{~s}^{-1}$ (trace a), $5.9 \times 10^{-2} \mathrm{~s}^{-1}$ (trace b), and $1.6 \times 10^{-1} \mathrm{~s}^{-1}$ (trace c). (C) Normalized averaged time courses for cyanide binding to $\mathrm{Cj}$ trHbP(III). For clarity, trace $a$ and trace $b$ have been upshifted by 0.6 and 0.3 , respectively. The cyanide concentration was $1.0 \times 10^{-6} \mathrm{M}$ (trace a), $1.0 \times 10^{-5} \mathrm{M}$ (trace b), and $1.0 \times 10^{-3} \mathrm{M}$ (trace c). The time course analysis according to Eqns $(3 a, 3 b)$ [21] yielded the following values of $l_{\text {obs: }}: 1.8 \times 10^{-3} \mathrm{~s}^{-1}$ (trace a), $1.9 \times 10^{-3} \mathrm{~s}^{-1}$ (trace b), and $2.1 \times 10^{-3} \mathrm{~s}^{-1}$ (trace c). (D) Dependence of the pseudo-first-order rate constant $l_{\text {obs }}$ for cyanide binding to $M t$-trHbN(III) (squares) and $M t$-trHbO(III) (circles) on ligand concentration (i.e. cyanide concentration). The analysis of data for cyanide binding to $M t$-trHbN(III) and $M t$-trHbO(III) according to Eqn $(2)$ [18,21] yielded the following values of $I_{\text {on }}$ : $(3.8 \pm 0.4) \times 10^{2} \mathrm{M}^{-1} \cdot \mathrm{s}^{-1}$ and $(3.2 \pm 0.4) \times 10^{2} \mathrm{M}^{-1} \cdot \mathrm{s}^{-1}$, respectively. (E) Dependence of the pseudo-first-order rate constant $\mathrm{l}_{\text {obs }}$ for cyanide binding to $\mathrm{C}$-trHbP(III) on ligand concentration (i.e. cyanide concentration). The $\mathrm{pH}$-independent value of $\mathrm{l}_{\text {obs }}$ is $(1.9 \pm 0.3) \times 10^{-3} \mathrm{~s}^{-1}$. Data referring to cyanide binding to $\mathrm{Mt}$ $\operatorname{tr} \mathrm{HbN}(\mathrm{III})$ and $\mathrm{Mt}$-trHbO(III) were obtained from Milani et al. [18]. The protein concentration ranged between $2.0 \times 10^{-7} \mathrm{M}$ and $5.0 \times 10^{-6} \mathrm{M}$. All data were obtained at $\mathrm{pH} 7.0$ and $20.0^{\circ} \mathrm{C}$. For details, see text. 
Table 1. Values of kinetic and thermodynamic parameters for cyanide binding to ferric and ferrous heme-proteins. Values in italic were calculated according to the following equations: $L=I_{\text {off }} / I_{\text {on }}$ and $K=k_{\text {off }} / k_{\text {on }}$.

\begin{tabular}{|c|c|c|c|c|c|c|}
\hline \multirow[b]{2}{*}{ (Non)vertebrate globin } & \multicolumn{3}{|l|}{$\mathrm{Fe}(\mathrm{III})$} & \multicolumn{3}{|l|}{$\mathrm{Fe}(\mathrm{II})$} \\
\hline & Ion $\left(\mathrm{M}^{-1} \cdot \mathrm{s}^{-1}\right)$ & $I_{\text {off }}\left(s^{-1}\right)$ & $L(\mathrm{M})$ & $k_{\text {on }}\left(\mathrm{M}^{-1} \cdot \mathrm{s}^{-1}\right)$ & $k_{\mathrm{off}}\left(\mathrm{s}^{-1}\right)$ & $K(\mathrm{M})$ \\
\hline$M t-\mathrm{trHbN}$ & $3.8 \times 10^{2 a}$ & $6.8 \times 10^{-4}$ & $1.8 \times 10^{-6 b}$ & $5.0 \times 10^{-2 b}$ & $\begin{array}{l}1.3 \times 10^{-2 b} \\
1.2 \times 10^{-2 a}\end{array}$ & $\begin{array}{l}2.4 \times 10^{-1 b} \\
2.4 \times 10^{-1}\end{array}$ \\
\hline$M t-\mathrm{trHbO}$ & $3.2 \times 10^{2 a}$ & $3.5 \times 10^{-4}$ & $1.1 \times 10^{-6 b}$ & $8.5 \times 10^{-2 b}$ & $\begin{array}{l}1.3 \times 10^{-2 b} \\
1.3 \times 10^{-2 a}\end{array}$ & $\begin{array}{l}1.6 \times 10^{-1 b} \\
1.5 \times 10^{-1}\end{array}$ \\
\hline Cj-trHbP & $\geq 2 \times 10^{4 b}$ & $\geq 1 \times 10^{-4}$ & $5.8 \times 10^{-9 b}$ & $3.3 \times 10^{3 b}$ & $\begin{array}{l}4.0 \times 10^{-3} \\
5.0 \times 10^{-3 c}\end{array}$ & $\begin{array}{l}1.2 \times 10^{-6 b} \\
1.7 \times 10^{-6}\end{array}$ \\
\hline Sperm whale Mb & $1.8 \times 10^{2 d}$ & $8.0 \times 10^{-4 d}$ & $4.3 \times 10^{-6}$ & - & $2.1 \times 10^{-2 e}$ & $4.0 \times 10^{-1 f}$ \\
\hline Horse heart Mb & $1.7 \times 10^{2 \mathrm{~g}}$ & $3.0 \times 10^{-3}$ & $1.8 \times 10^{-5 g}$ & $2.5^{\mathrm{h}}$ & $1.5 \times 10^{-1 i}$ & $\begin{array}{l}4.0 \times 10^{-1 h} \\
5.8 \times 10^{-2}\end{array}$ \\
\hline S. inaequivalvis $\mathrm{Hbl}^{\mathrm{h}}$ & $2.3 \times 10^{2}$ & $6.2 \times 10^{-6}$ & $2.7 \times 10^{-8}$ & 2.7 & $1.1 \times 10^{-2}$ & $\begin{array}{l}5.8 \times 10^{-2} \\
4.0 \times 10^{-3}\end{array}$ \\
\hline Human $\mathrm{Hb}$ & $1.1 \times 10^{2 j}$ & $1.4 \times 10^{-7}$ & $1.3 \times 10^{-9 k}$ & $\begin{array}{l}- \\
-\end{array}$ & $\begin{array}{l}\text { (R-state) } 1.2 \times 10^{-11} \\
\text { (T-state) } 1.5^{\prime}\end{array}$ & $\begin{array}{l}\sim 1^{\mathrm{m}} \\
-\end{array}$ \\
\hline Horseradish peroxidase & $9.0 \times 10^{4 n}$ & $2.8 \times 10^{-1 n}$ & $\begin{array}{l}2.4 \times 10^{-6 n} \\
2.9 \times 10^{-6}\end{array}$ & $2.9 \times 10^{10}$ & $2.5 \times 10^{-20}$ & $\begin{array}{l}5.0 \times 10^{-40} \\
8.6 \times 10^{-4}\end{array}$ \\
\hline
\end{tabular}

${ }^{\mathrm{a}} \mathrm{pH} 7.0,20.0{ }^{\circ} \mathrm{C}$ [18]. ${ }^{\mathrm{b}} \mathrm{pH} 7.0,20.0{ }^{\circ} \mathrm{C}$ (present study). ${ }^{\mathrm{c}} \mathrm{pH} 7.0,20.0{ }^{\circ} \mathrm{C}$ [16]. ${ }^{\mathrm{d}} \mathrm{pH} 6.6,25.0{ }^{\circ} \mathrm{C}$ [27]. ${ }^{\mathrm{e}} \mathrm{pH} 7.0,20.0{ }^{\circ} \mathrm{C}$ [37]. ${ }^{\mathrm{f}} \mathrm{pH}$ 9.3, $20.0{ }^{\circ} \mathrm{C}$ [27]. ${ }^{\mathrm{g}} \mathrm{pH} 7.0,22.0^{\circ} \mathrm{C}$ [21]. ${ }^{\mathrm{h}} \mathrm{pH}$ 9.2, $20.0{ }^{\circ} \mathrm{C}$ [30]. ${ }^{\mathrm{i}} \mathrm{pH} 8.2,25.0^{\circ} \mathrm{C}$ [36]. ${ }^{\mathrm{j}} \mathrm{pH} 6.05,20.0{ }^{\circ} \mathrm{C}$ [25]. ${ }^{\mathrm{k}} \mathrm{pH} 7.0,20{ }^{\circ} \mathrm{C}$ [21]. ${ }^{\prime} \mathrm{pH} 7.0$, $20.0^{\circ} \mathrm{C}$ [38]. ${ }^{\mathrm{m}} \mathrm{pH} \sim 10.6$; the temperature is unknown [33]. ${ }^{\mathrm{n}} \mathrm{pH} 7.05,25.0^{\circ} \mathrm{C}$ [24]. ${ }^{\circ} \mathrm{pH} 9.1,20.0{ }^{\circ} \mathrm{C}$ [35].
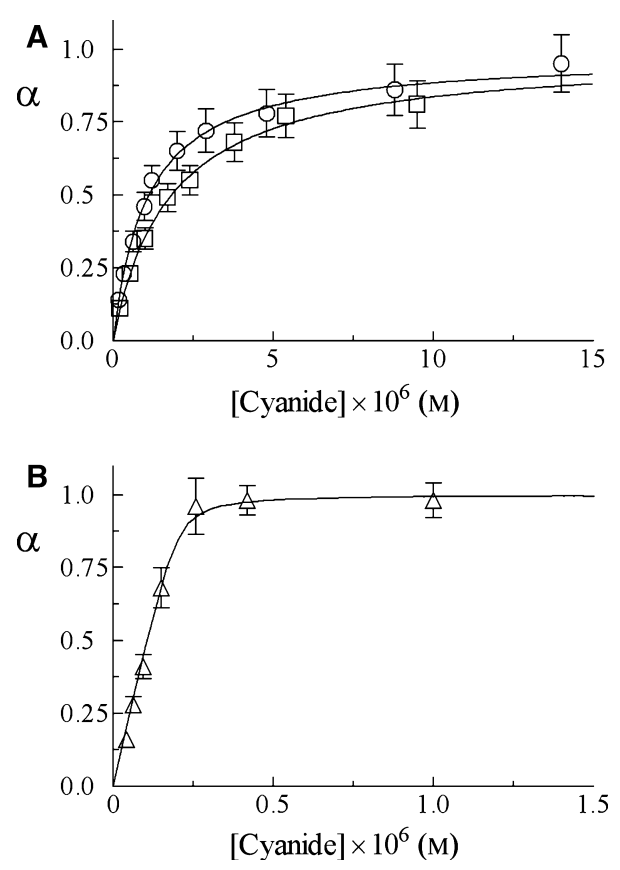

Fig. 3. Ligand-binding isotherms for cyanide association with $M t$ $\operatorname{trHbN(III)}$ (A, squares), $M t$-trHbO(III) (A, circles), and $\mathrm{Cj-trHbP(III)}$ (B). The analysis of data for cyanide association with $M t-\operatorname{tr} H b N(I I I)$, $\mathrm{Mt}$-trHbO(III) and $\mathrm{C} j$-trHbP(III) according to Eqn (5) [23] yielded the following values of $L$ : $(1.8 \pm 0.2) \times 10^{-6} \mathrm{M},(1.1 \pm 0.1) \times 10^{-6} \mathrm{M}$, and $(5.8 \pm 0.6) \times 10^{-9} \mathrm{M}$, respectively. The protein concentration ranged between $2.0 \times 10^{-7} \mathrm{M}$ and $2.2 \times 10^{-7} \mathrm{M}$. All data were obtained at $\mathrm{pH} 7.0$ and $20.0^{\circ} \mathrm{C}$. For details, see text. conformational transition(s) $\quad\left[l_{\max }=(2.0 \pm 0.3) \times\right.$ $10^{-3} \mathrm{~s}^{-1}$, independent of the ligand concentration] (Fig. 2), a feature never observed within heme(III) proteins.

The reaction of cyanide with heme(II) proteins has received little attention, due to the low stability of the heme-Fe(II)-ligand complexes $\left(K \geq 5.8 \times 10^{-2} \mathrm{M}\right)$ [18,27,30,33-40]. $C j$-trHbP(II) and horseradish peroxidase are two exceptions in this respect, as values of the cyanide dissociation equilibrium constant (i.e. $K$ ) are $1.2 \times 10^{-6} \mathrm{M}$ and $5.0 \times 10^{-4} \mathrm{M}$ [35], respectively (Table 1). Values of $k_{\text {off }}$ range between $5 \times 10^{-3} \mathrm{~s}^{-1}$ and $1.5 \mathrm{~s}^{-1}$, whereas values of $k_{\text {on }}$ range between $5 \times 10^{-2} \mathrm{M}^{-1} \cdot \mathrm{s}^{-1}$ and $3.3 \times 10^{3} \mathrm{M}^{-1} \cdot \mathrm{s}^{-1} \quad[18,27,30,33$, $35,36,38-40]$; in this context, $C j$-trHbP(II) shows the highest and the lowest values for $k_{\text {on }}$ and $k_{\text {off }}$, respectively (Table 1). As reported for $C j$-trHbP(III) (Fig. 2), the kinetics of cyanide binding to $C j$-trHbP(II) (Fig. 4) are limited by conformational transition(s), the apparent rate constant tending to be independent of the ligand concentration at cyanide concentrations $>3.0 \times 10^{-3}$ M (i.e. $k_{\max }=9.1 \mathrm{~s}^{-1}$ ) (Fig. 4).

Values of $K$ for cyanide binding to Scapharca inaequivalvis $\mathrm{HbI}(\mathrm{II})$ and horse heart myoglobin (Mb)(II) measured in equilibrium experiments are about 10 -fold lower than those obtained from the ratio of the association and dissociation rate constants (Table 1), possibly reflecting the formation of metastable intermediate(s) $[30,36,41,42]$. In contrast, the excellent 

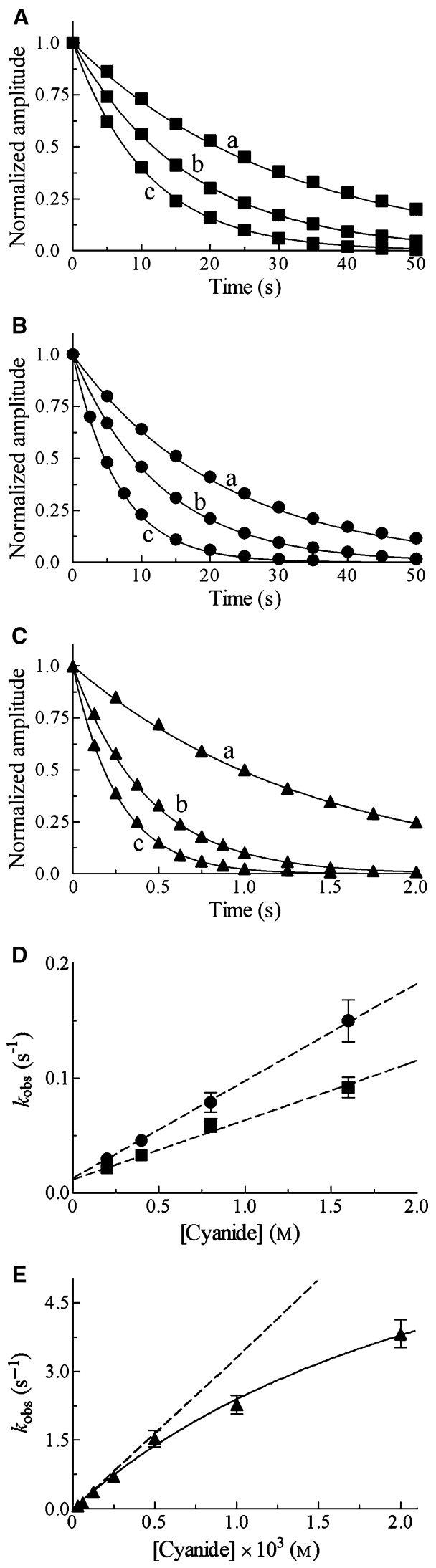

agreement between values of $K$ obtained at equilibrium and from the ratio of the association and dissociation rate constants for cyanide binding to $M t$-trHbN(II), $M t$-trHbO(II) and $C j$-trHbP(II) (Table 1) excludes the occurrence of metastable intermediate(s) in the formation and dissociation of the $\operatorname{tr} \mathrm{Hb}(\mathrm{II})$-cyanide species.

$C j$-trHbP(II) shows ligand-binding properties reminiscent of those of horseradish peroxidase(II). In fact, even though horseradish peroxidase(II) shows a relatively high reactivity towards cyanide [35] when compared to that of ferrous 2-on-2 and 3-on-3 globins $[16,18,27,30,33,36-38]$, it turns out to be $\sim 100$-fold slower than what was observed for $C j$-trHbP(II) (Table 1). Furthermore, values of the second-order rate constant for $\mathrm{O}_{2}, \mathrm{CO}$ and cyanide binding to horseradish peroxidase(II) $\left(5.7 \times 10^{4} \mathrm{M}^{-1} \cdot \mathrm{s}^{-1} \quad\right.$ [43]), $4.0 \times 10^{3} \mathrm{M}^{-1} \cdot \mathrm{s}^{-1} \quad[44,45]$, and $2.9 \times 10^{1} \mathrm{M}^{-1} \cdot \mathrm{s}^{-1}[35]$, respectively) span over three orders of magnitude, as observed for $C j$-trHbP(II) $\left[9.1 \times 10^{5} \mathrm{M}^{-1} \cdot \mathrm{s}^{-1} \quad[16]\right.$; $1.1 \times 10^{5} \mathrm{M}^{-1} \cdot \mathrm{s}^{-1} \quad$ (Coletta $\mathrm{M} \&$ Guertin $\mathrm{M}$, unpublished results); and $3.3 \times 10^{3} \mathrm{M}^{-1} \cdot \mathrm{s}^{-1}$ (present study)]. In contrast, values of kinetic and thermodynamic parameters for $\mathrm{O}_{2}, \mathrm{CO}$ and cyanide binding to ferrous 2-on-2 and 3-on-3 globins [e.g. $M t$-trHb(II) and sperm

Fig. 4. Kinetics of cyanide binding to $M t-\operatorname{tr} H b N(I I), M t-\operatorname{tr} H b O(I I)$, and $\mathrm{Cj}$-trHbP(II). (A) Normalized averaged time courses for cyanide binding to $\mathrm{Mt}$-trHbN(II). The cyanide concentration was $4.0 \times 10^{-1} \mathrm{M}$ (trace a), $8.0 \times 10^{-1} \mathrm{M}$ (trace b), and $1.6 \mathrm{M}$ (trace c). The time course analysis according to Eqn (6) [21] yielded the following values of $k_{\text {obs }}$ : $3.3 \times 10^{-2} \mathrm{~s}^{-1}$ (trace a), $5.9 \times 10^{-2} \mathrm{~s}^{-1}$ (trace b), and $9.8 \times 10^{-2} \mathrm{~s}^{-1}$ (trace c). (B) Normalized averaged time courses for cyanide binding to $\mathrm{Mt}$-trHbO(II). The cyanide concentration was $4.0 \times 10^{-1} \mathrm{M}$ (trace a), $8.0 \times 10^{-1} \mathrm{M}$ (trace b), and $1.6 \mathrm{M}$ (trace c). The time course analysis according to Eqn (6) [21] yielded the following values of $k_{\text {obs }}: 4.6 \times 10^{-2} \mathrm{~s}^{-1}$ (trace a), $7.9 \times 10^{-2} \mathrm{~s}^{-1}$ (trace b), and $1.5 \times 10^{-1} \mathrm{~s}^{-1}$ (trace c). (C) Normalized averaged time courses for cyanide binding to $\mathrm{Cj}$-trHbP(II). The cyanide concentration was $2.5 \times 10^{-4} \mathrm{M}$ (trace a), $1.0 \times 10^{-3} \mathrm{M}$ (trace b), and $2.0 \times 10^{-3} \mathrm{M}$ (trace $\mathrm{c}$ ). The time course analysis according to Eqns (8a,8b) [21] yielded the following values of $k_{\mathrm{obs}}: 7.1 \times 10^{-1} \mathrm{~s}^{-1}$ (trace a), $2.3 \mathrm{~s}^{-1}$ (trace b), and $3.8 \mathrm{~s}^{-1}$ (trace c). (D, E) Dependence of the pseudo-first-order rate-constant $k_{\mathrm{obs}}$ for cyanide binding to $M t-\operatorname{trHbN}(I I)$ (D, squares), $M t$-trHbO(II) (D, circles) and $C j$-trHbP(II) (E) on the ligand concentration (i.e. cyanide concentration). The analysis of data for cyanide binding to $\mathrm{Mt}$-trHbN(II) and $\mathrm{Mt}$-trHbO(II) according to Eqn (7) (dashed line) [21] yielded the following values of $k_{\text {on }}:(5.0 \pm 0.6) \times 10^{-2} \mathrm{M}^{-1} \cdot \mathrm{s}^{-1}$ and $(8.5 \pm 0.9) \times 10^{-2} \mathrm{M}^{-1} \cdot \mathrm{s}^{-1}$, respectively. The value of $k_{\text {off }}$ for cyanide dissociation from $\mathrm{Mt}$-trHbN(II)-cyanide and $\mathrm{Mt}$-trHbO(II)-cyanide is $(1.3 \pm 0.2) \times$ $10^{-2} \mathrm{~s}^{-1}$. The analysis of data for cyanide binding to $\mathrm{C}$-trHbP(II) according to Eqn (9) (solid line) [22] and Eqn (10) (dashed line) [22] yielded $\left.K_{\text {pre }}=(2.8 \pm 0.3) \times 10^{-3} \mathrm{M}\right), \quad k_{\max }=9.1 \pm 0.8 \mathrm{~s}^{-1}$, and $k_{\text {on }}=k_{\text {max }} / K_{\text {pre }}=(3.3 \pm 0.4) \times 10^{3} \mathrm{M}^{-1} \cdot \mathrm{s}^{-1}$. The protein concentration ranged between $2.9 \times 10^{-6} \mathrm{M}$ and $3.6 \times 10^{-6} \mathrm{M}$. All data were obtained at $\mathrm{pH} 7.0$ and $20.0^{\circ} \mathrm{C}$. For details, see text. 

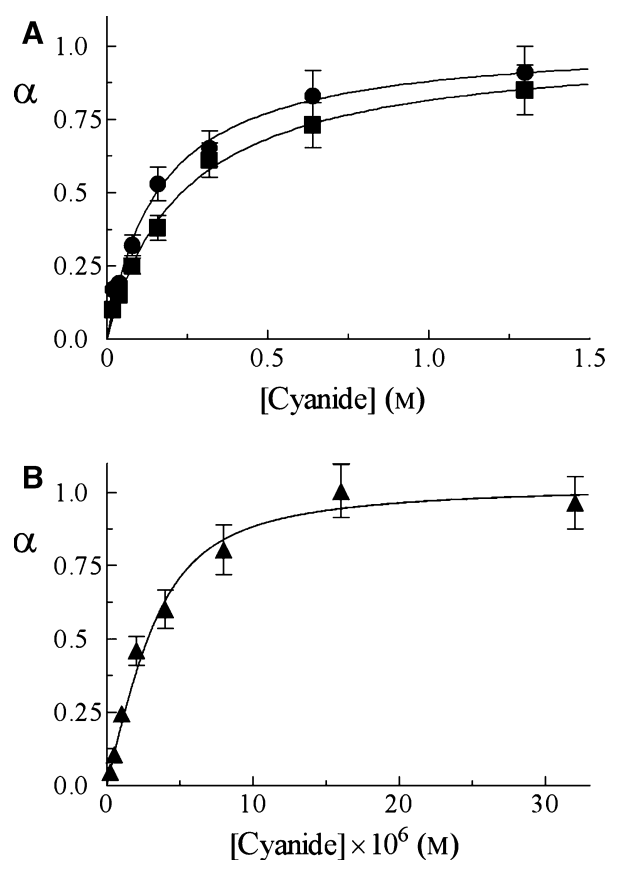

Fig. 5. Ligand-binding isotherms for cyanide association with $M t$-trHbN(II) (A, squares), $M t$-trHbO(II) (A, circles), and $C$-trHbP(II) (B). The analysis of data for cyanide association with $\mathrm{Mt}$-trHbN(II),

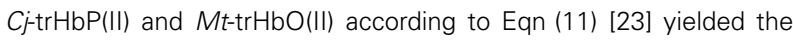
following values of $K:(2.4 \pm 0.3) \times 10^{-1} \mathrm{M},(1.6 \pm 0.2) \times 10^{-1} \mathrm{M}$, and $1.2 \pm 0.2) \times 10^{-6} \mathrm{M}$, respectively. The protein concentration ranged between $2.3 \times 10^{-6} \mathrm{M}$ and $3.5 \times 10^{-6} \mathrm{M}$. All data were obtained at $\mathrm{pH} 7.0$ and $20.0^{\circ} \mathrm{C}$. For details, see text.

whale $\mathrm{Mb}(\mathrm{II})$ ] span over nine orders of magnitude $[1,21,46,47]$. Therefore, $C j$-trHbP(II) and horseradish peroxidase discriminate among different ligands much less than do ferrous 2-on-2 and 3-on-3 globins [e.g. $M t$-trHb(II) and sperm whale $\mathrm{Mb}(\mathrm{II})]$. Such observations might be in keeping with the postulated involvement of $C j$-trHbP in $\mathrm{O}_{2}$ chemistry, like peroxidase, rather than in $\mathrm{O}_{2}$ transport, which may require specific adaptations to different environmental conditions [17].

The affinity of cyanide for heme(III) proteins appears to depend on the presence of heme distal site proton acceptor and donor group(s) that may assist the deprotonation of the incoming ligand, or the protonation of the outgoing cyanide anion [18]. This interpretation is in agreement with the very slow kinetics of cyanide binding to Glycera dibranchiata monomeric $\mathrm{HbC}(\mathrm{III})$, whose heme distal site lacks residue(s) capable of catalyzing proton exchange, and with the effects shown by changes in the polarity of the heme distal pocket of mutated human, pig and sperm whale Mbs $[1,20,21,48]$.

Concerning $C j$-trHbP(III), the crystal structure shows that the stabilization of the heme-bound cyanide is achieved through direct hydrogen bonds of the ligand to residue TyrB10 (phenolic $\mathrm{OH}$ group) and to the indole nitrogen atom of TrpG8 (Fig. 6). Such interactions, together with the presence of a water molecule, trapped in the heme distal site and hydrogen-bonded to TyrB10 (Fig. 6), may assist the proton exchange processes required for efficient heme-ligand association/dissociation. In a dynamic protein context, the contribution of HisE7, shown to adopt different conformations in $C j$-trHbP(III) crystals, might also be considered either in direct ligand interactions or in affecting the conformation of neighboring polar residues $[16,17]$.

The crystal structure of the cyanide derivative of $M t$-trHbN(III) shows that only one direct hydrogen bond (to TyrB10) stabilizes the heme-bound cyanide; a second hydrogen-bonding contribution may be provided by the nearby GlnE11 residue (Fig. 6), substituting for a generally apolar residue (Val, Ile, and Leu) at this site in vertebrate Hbs. The access to the heme distal site of $M t$-trHb through the E7-gate appears to be precluded by the location of the E-helix and by residue LeuE7 [49]. However, heme ligands may diffuse though (apolar) protein matrix tunnels, which have been mapped in the crystal structures of $M t$-trHbN xenon derivatives [50]. Stabilization of the heme-bound cyanide in group II $M t$-trHbO(III) takes place through two hydrogen bonds, provided by the side chain of TyrCD1 and by the indole nitrogen atom of TrpG8 (in a dynamic context, TyrB10 may also be part of such a ligand hydrogen-bonded network) (Fig. 6). Access to the heme distal site through the E7-gate is possible in $M t$-trHbO, given the small size of residue AlaE7 [51].

The comparison of the crystal structures of the cyanide derivatives of $M t$-trHbN(III), $M t$-trHbO(III) and $C j$-trHbP(III) suggests that diverse ligand diffusion paths and binding mechanisms are active in the three trHb groups. Although in all three groups the heme ligand eventually becomes part of a hydrogen-bonded network involving heme distal residues, the nature and the involvement of residues at sites CD1, E7, E11 and G8 varies in a group-specific fashion, giving rise to different stabilization patterns for the heme-bound cyanide (Fig. 6) [16,49,51].

It appears worth noticing that $C j$-trHbP displays the highest affinity as well as the fastest combination and the slowest dissociation rate for cyanide binding of the known members of the $\mathrm{Hb}$ superfamily. Furthermore, as the kinetics of cyanide binding to $C j$-trHbP appear to be limited by conformational transition(s) with firstorder rate constants dependent on the oxidation state of the heme iron atom, $C j$-trHbP may represent a 

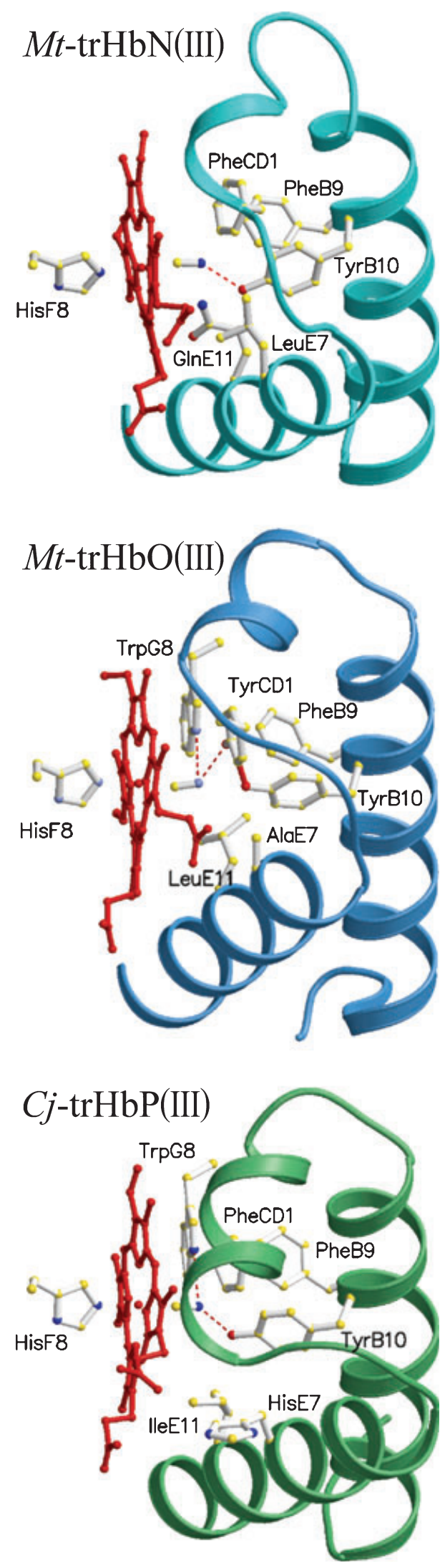

reference system for investigating the interplay between the redox state of the heme iron atom and conformational transition(s) modulating trHb reactivity.

Finally, the very high affinity of cyanide for $C j$-trHbP suggests that this globin may participate in cyanide detoxification, facilitating the survival of C. jejuni. Indeed, the intestinal localization of $C$. jejuni in herbivores suggests that this organism could be exposed to cyanide generated from the enzymatic breakage of cyanogenic glycosides of ingested plants [19]. Interestingly, inspection of the C. jejuni NCTC11168 genome (http://campy.bham.ac.uk/) reveals that this bacterium lacks proteins that have been annotated as canonical double-domain rhodaneses, although it contains two putative proteins with a rhodanese (RHOD) module (NCBI accession numbers CAL34666 and CAL34648). Moreover, C. jejuni expresses a cyanide-resistant lowaffinity terminal oxidase (not of the cytochrome $b d$ type) encoded by $c y d A B$ genes [52], which could facilitate survival in cyanide-containing environments.

\section{Experimental procedures}

\section{Materials}

Cloning, expression and purification of $C j$-trHbP were performed as previously reported [16]. $M t-\mathrm{TrHbN}$ and $M t$-trHbO were cloned, expressed and purified as previously reported [53,54]. $M t$-trHbN(III), $M t$-trHbO(III) and $C j$-trHbP(III) were prepared by adding a few grains of ferricyanide to the trHb solution [21]. $M t$-trHbN(II), $M t$ $\operatorname{tr} \mathrm{HbO}(\mathrm{II})$ and $C j$-trHbP(II) were prepared by adding a few grains of dithionite to the trHb solution, under anaerobic conditions [21]. All chemicals (from Merck AG, Darmstadt, Germany) were of analytical grade and were used without further purification.

\section{Kinetics of cyanide binding to $M t$-trHbN(III) and Mt-trHbO(III)}

The kinetics of cyanide binding to $M t$-trHbN(III) and $M t$ $\operatorname{trHbO}(\mathrm{III})$ were measured by mixing a protein-buffered solution $\left(2.0 \times 10^{-6} \mathrm{M}\right.$ and $5.0 \times 10^{-6} \mathrm{M}, \quad$ respectively $)$

Fig. 6. View of the heme distal pocket of the cyanide derivative of $M t$-trHbN(III) (Protein Data Bank code: 1RTE [18]), Mt-trHbO(III) (Protein Data Bank code: 1NGH [51]), and Cj-trHbP(III) (Protein Data Bank code: 2IG3 [16]), displaying part of the surrounding protein structure (ribbon), the heme group (red), the cyanide ligand, and key residues stabilizing the heme Fe-bound cyanide. Hydrogen bonds stabilizing the heme Fe-bound cyanide are represented by dashed red lines. All pictures were drawn with MOLSCRIPT [55]. For details, see text. 
Table 2. Values of $\lambda_{\max }$ and $\varepsilon$ of the absorption spectra in the Soret region of ferric [i.e. Fe(III) and Fe(III)-cyanide] and ferrous [i.e. Fe(II) and Fe(II)-cyanide] derivatives of $M t$-trHbN, Mt-trHbO, and $C j$-trHbP. Values of $\lambda_{\max }(\mathrm{nm})$ are in italic and values of $\varepsilon\left(\mathrm{mM}^{-1} \mathrm{~cm}^{-1}\right)$ are in bold.

\begin{tabular}{lllll}
\hline Protein & Fe(III) & Fe(III)-cyanide & Fe(II) & Fe(II)-cyanide \\
\hline Mt-trHbN $^{\mathrm{a}}$ & 406 & 418 & 432 & 435 \\
& $\mathbf{1 4 1}$ & $\mathbf{1 0 2}$ & $\mathbf{1 0 3}$ & $\mathbf{1 4 2}$ \\
Mt-trHbO $^{\mathrm{b}}$ & 409 & 419 & 429 & 436 \\
& $\mathbf{1 0 4}$ & $\mathbf{1 0 5}$ & $\mathbf{9 2}$ & $\mathbf{1 4 4}$ \\
Cj-trHbP & $410^{\mathrm{c}}$ & $420^{\mathrm{d}}$ & $433^{\mathrm{d}}$ & $434^{\mathrm{d}}$ \\
& $\mathbf{1 4 1}^{\mathrm{c}}$ & $\mathbf{1 1 2}^{\mathrm{d}}$ & $\mathbf{1 1 9}^{\mathrm{d}}$ & $\mathbf{1 7 4}^{\mathrm{d}}$
\end{tabular}

${ }^{\mathrm{a}} \mathrm{pH} 7.0$ and $20.0^{\circ} \mathrm{C}$ [18]. ${ }^{\mathrm{b}} \mathrm{pH} 7.0$ and $20.0^{\circ} \mathrm{C} \mathrm{[18].}{ }^{\mathrm{c}} \mathrm{pH} 7.0$ and $20.0^{\circ} \mathrm{C}$ (present study). ${ }^{\mathrm{d}} \mathrm{pH} 7.0$ and $20.0^{\circ} \mathrm{C}$ [16].

with a cyanide-buffered solution (from $5.0 \times 10^{-5} \mathrm{M}$ to $\left.1.0 \times 10^{-3} \mathrm{M}\right)$. The reaction was monitored between $380 \mathrm{~nm}$ and $460 \mathrm{~nm}$ (Table 2), using the SFM-20 rapid-mixing stopped-flow apparatus (Bio-Logic SAS, Claix, France). No gaseous phase was present [18].

Values of the first-order rate constant for cyanide binding to $M t$-trHbN(III) and $M t$-trHbO(III) $\left(l_{\text {obs }}\right)$ were calculated according to Eqn (1) [18,21]:

$$
[M t-\operatorname{trHb}(\mathrm{III})]_{t}=[M t-\operatorname{trHb}(\mathrm{III})]_{i} \times e^{-l_{\mathrm{obs}} \times \mathrm{t}}
$$

The dependence of $l_{\mathrm{obs}}$ on cyanide concentration for ligand binding to $M t$-trHbN(III) and $M t$-trHbO(III) was analyzed according to the minimum reaction mechanism shown in Scheme 1 [18]:

$$
M t \text {-trHb(III) }+ \text { cyanide } \underset{l_{\text {off }}}{\stackrel{l_{\text {on }}}{\leftrightarrows}} M t \text {-trHb(III)-cyanide (Scheme 1) }
$$

where $l_{\text {on }}$ is the second-order rate constant for cyanide binding to $M t$-trHbN(III) and $M t$-trHbO(III) (i.e. for the formation of $M t$-trHbN(III)-cyanide and $M t$-trHbO(III)cyanide), and $l_{\text {off }}$ is the first-order rate constant for cyanide dissociation from $M t$-trHbN(III)-cyanide and $M t$-trHbO(III)-cyanide.

Values of $l_{\text {on }}$ were obtained according to Eqn (2) $[18,21]$ :

$$
l_{\mathrm{obs}}=l_{\mathrm{on}} \times[\text { cyanide }]
$$

\section{Kinetics of cyanide binding to $C_{j}$-trHbP(III)}

The kinetics of cyanide binding to $C j$-trHbP(III) were measured by mixing a protein-buffered solution $\left(2.0 \times 10^{-7} \mathrm{M}\right)$ with a cyanide-buffered solution (from $1.0 \times 10^{-6} \mathrm{M}$ to $\left.1.0 \times 10^{-3} \mathrm{M}\right)$. The reaction was followed spectrophotometrically between $350 \mathrm{~nm}$ and $460 \mathrm{~nm}$ (see Table 2). Absorbance spectra were recorded every $3 \mathrm{~min}$. No gaseous phase was present [18].

Values of the first-order rate constant for cyanide binding to $C j$-trHbP(III) $\left(l_{\text {obs }}\right)$ were calculated according to Eqn (3) [21]:

$$
\begin{array}{r}
{[C j-\operatorname{trHbP}(\mathrm{III})]_{t}=[C j-\operatorname{trHbP}(\mathrm{III})]_{i} \times e^{-l_{\mathrm{obs}} \times t}} \\
{[C j-\operatorname{trHbP}(\mathrm{III})]_{t}=[C j-\operatorname{trHbP}(\mathrm{III})]_{i} \times\left(1-e^{-l_{\mathrm{obs}} \times t}\right)}
\end{array}
$$

The dependence of $l_{\text {obs }}$ on cyanide concentration for ligand binding to $C j$-trHbP(III) was analyzed according to the minimum reaction mechanism shown in Scheme 2 [22]:

$$
\begin{aligned}
& C j \text {-trHbP(III) }+ \text { cyanide } \underset{l_{-1}}{\stackrel{l_{+1}}{\leftrightarrows}}(C j \text {-trHbP(III)-cyanide })_{1} \\
& \stackrel{l_{+2}}{\stackrel{l_{-2}}{(}}(C j-\operatorname{trHbP}(\mathrm{III})-\text { cyanide })_{2}
\end{aligned}
$$

(Scheme 2)

where $l_{+1} \quad\left(=l_{\text {on }}=l_{\max } / L_{\text {pre }}\right)$ is the second-order rate constant for cyanide binding to $C j$-trHbP(III) [i.e. for the formation of the transient $(C j \text {-trHbP(III)-cyanide })_{1}$ species], $l_{-1} / l_{+1}\left(=L_{\text {pre }}\right)$ is the pre-equilibrium constant, $l_{+2}\left(=l_{\max }\right)$ represents the asymptotic value of $l_{\mathrm{obs}}$ for cyanide concentration $\geq 10 \times L_{\text {pre }}$, and $l_{-2}\left(=l_{\text {off }}\right)$ is the first-order rate constant for cyanide dissociation from the final $\mathrm{Cj}$ trHbP(III)-cyanide complex, [i.e. $C j$-trHbP(III)-cyanide) $)_{2}$ ]. Step 1 of Scheme 2 (characterized by $l_{+1}$ and $l_{-1}$ ) is not a simple process but represents a multistep reaction reflecting the dynamic pathway of the ligand from the bulk solvent to the heme pocket, where it reacts with the heme Fe(III) atom (i.e. step 2 of (Scheme 2), characterized by $l_{+2}$ and $l_{-2}$ ).

Values of $l_{\text {on }}, l_{\max }$ and $L_{\text {pre }}$ were estimated according to Eqn (4) [22]:

$$
l_{\mathrm{obs}}=l_{\max } \times[\text { cyanide }] /\left(L_{\mathrm{pre}}+[\text { cyanide }]\right)
$$

\section{Thermodynamics of cyanide binding to Mt-trHbN(III), Mt-trHbO(III), and Cj-trHbP(III)}

The thermodynamics of cyanide binding to $M t$-trHbN(III), $M t$-trHbO(III) and $C j$-trHbP(III) were determined by adding a cyanide-buffered solution (from $4.1 \times 10^{-8} \mathrm{M}$ to $\left.1.8 \times 10^{-5} \mathrm{M}\right)$ to a protein-buffered solution ([Mt$\operatorname{trHbN}(\mathrm{III})]=2.2 \times 10^{-7} \mathrm{M}, \quad[M t$-trHbO(III) $]=2.1 \times 10^{-7}$ $\mathrm{M}$, and $\left.[C j-\operatorname{trHbP}(\mathrm{III})]=2.0 \times 10^{-7} \mathrm{M}\right)$. The reaction was followed spectrophotometrically between $350 \mathrm{~nm}$ and $460 \mathrm{~nm}$ (see Table 2). Absorbance spectra were recorded after achieving the equilibrium (the equilibration time ranged between $1 \mathrm{~h}$ and $48 \mathrm{~h}$ ). No gaseous phase was present.

The dependence of the molar fraction of cyanide-bound $\operatorname{trHb}(\mathrm{III})$ (i.e. $\alpha$ ) on cyanide concentration was analyzed according to the minimum reaction mechanism shown in Scheme 3 [21]:

$$
\operatorname{trHb}(\mathrm{III})+\text { cyanide } \underset{l_{\text {off }}}{\stackrel{l_{\text {on }}}{\leftrightarrows}} \operatorname{trHb}(\mathrm{III})-\text { cyanide }
$$

(Scheme 3)

Values of the dissociation equilibrium constant for cyanide binding to $M t$-trHbN(III), $M t$-trHbO(III) and $C j$-trHbP(III) $\left(L=l_{\text {off }} / l_{\text {on }}\right)$ were calculated according to Eqn (5) [23]: 


$$
\begin{aligned}
\alpha= & (-([\text { cyanide }]+L+[\operatorname{trHb}(\mathrm{III})])+\sqrt{ }(([\text { cyanide }]+L \\
& \left.\left.+[\operatorname{trHb}(\mathrm{III})])^{2}-4 \times[\text { cyanide }] \times[\operatorname{trHb}(\mathrm{III})]\right)\right) / \\
& (2 \times[\operatorname{trHb}(\mathrm{III})])
\end{aligned}
$$

\section{Kinetics of cyanide binding to Mt-trHbN(II) and Mt-trHbO(II)}

The kinetics of cyanide binding to $M t$ - $\operatorname{trHbN}(\mathrm{II})$ and $M t$ trHbO(II) were measured by mixing a protein-buffered solution $\left(2.9 \times 10^{-6} \mathrm{M}\right.$ and $3.6 \times 10^{-6} \mathrm{M}$, respectively $)$ with a cyanide-buffered solution (from $2.0 \times 10^{-1} \mathrm{M}$ to $1.6 \mathrm{M}$ ). The reaction was monitored between $350 \mathrm{~nm}$ and $460 \mathrm{~nm}$ (see Table 2) using the SFM-20 rapid-mixing stopped-flow apparatus (Bio-Logic SAS, Claix, France). No gaseous phase was present.

Values of the first-order rate constant for cyanide binding to $M t$-trHbN(II) and $M t$-trHbO(II) $\left(k_{\mathrm{obs}}\right)$ were calculated according to Eqn (6) [21]:

$$
[M t-\operatorname{trHb}(\mathrm{II})]_{t}=[M t-\operatorname{trHb}(\mathrm{II})]_{i} \times e^{-k_{\mathrm{obs}} \times t}
$$

The dependence of $k_{\mathrm{obs}}$ on cyanide concentration for ligand binding to $M t$-trHbN(II) and $M t$-trHbO(II) was analyzed according to the minimum reaction mechanism shown in Scheme 4 [21]:

$$
M t \text {-trHb(II) }+ \text { cyanide } \underset{k_{\text {off }}}{\stackrel{k_{\text {on }}}{\leftrightarrows}} M t \text {-trHb(II)-cyanide } \quad(\text { Scheme } 4)
$$

where $k_{\text {on }}$ is the second-order rate constant for cyanide binding to $M t$-trHbN(II) and $M t$-trHbO(II) [i.e. for the formation of $M t$-trHbN(II)-cyanide and $M t$-trHbO(II)-cyanide], and $k_{\text {off }}$ is the first-order rate constant for cyanide dissociation from $M t$-trHbN(II)-cyanide and $M t$ trHbO(II)-cyanide.

Values of $k_{\text {on }}$ and $k_{\text {off }}$ were obtained according to Eqn (7) [21]:

$$
k_{\text {obs }}=k_{\text {on }} \times[\text { cyanide }]+k_{\text {off }}
$$

\section{Kinetics of cyanide binding to $C_{j}$-trHbP(II)}

The kinetics of cyanide binding to $C j$-trHbP(II) were measured by mixing a protein-buffered solution $\left(3.5 \times 10^{-6} \mathrm{M}\right)$ with a cyanide-buffered solution (from $3.1 \times 10^{-5} \mathrm{M}$ to $\left.2.0 \times 10^{-3} \mathrm{M}\right)$. The reaction was monitored between $390 \mathrm{~nm}$ and $500 \mathrm{~nm}$ (see Table 2) using the rapid-mixing SX.18MV stopped-flow apparatus equipped with the PDA.1 photodiode array accessory (Applied Photophysics, Salisbury, UK). No gaseous phase was present.

Values of the first-order rate constant for cyanide binding to $C j$-trHbP(II) $\left(k_{\text {obs }}\right)$ were calculated according to Eqn (8) [21]:

$$
\begin{array}{r}
{[C j-\operatorname{trHbP}(\mathrm{II})]_{t}=[C j-\operatorname{trHbP}(\mathrm{II})]_{i} \times e^{-k_{\mathrm{obs}} \times t}} \\
{[C j-\operatorname{trHbP}(\mathrm{II})]_{t}=[C j-\operatorname{trHbP}(\mathrm{II})]_{i} \times\left(1-\mathrm{e}^{-k_{\mathrm{obs} \times t}}\right)}
\end{array}
$$

The dependence of $k_{\mathrm{obs}}$ on cyanide concentration for ligand binding to $C j$-trHbP(II) was analyzed according to the minimum reaction mechanism shown in Scheme 5 [22]:

$$
\begin{gathered}
C j-\operatorname{trHbP}(\mathrm{II})+\text { cyanide } \underset{k_{-1}}{\stackrel{k_{+1}}{\leftrightarrow}}(C j \text {-trHbP(II)-cyanide })_{1} \\
\stackrel{k_{-2}}{\stackrel{k_{+2}}{\longrightarrow}}(C j \text {-trHbP(II)-cyanide })_{2}
\end{gathered}
$$

(Scheme 5)

where $k_{+1}\left(=k_{\text {on }}=k_{\max } / K_{\text {pre }}\right)$ is the second-order rate constant for cyanide binding to $C j$-trHbP(II) [i.e. for the formation of the transient ( $C j$-trHbP(II)-cyanide) $)_{1}$ species], $k_{-1} / k_{+1}\left(=K_{\text {pre }}\right) \quad$ is the pre-equilibrium constant, $k_{+2}\left(=k_{\max }\right)$ represents the asymptotic value of $k_{\mathrm{obs}}$ for cyanide concentration $\geq 10 \times K_{\text {pre }}$, and $k_{-2}$ ( $\left.=k_{\text {off }}\right)$ is the first-order rate constant for cyanide dissociation from the final $C j$-trHbP(II)-cyanide complex [i.e. $(C j$-trHbP(II)cyanide) $)_{2}$. Step 1 of Scheme 5 (characterized by $k_{+1}$ and $k_{-1}$ ) is not a simple process but represents a multistep reaction reflecting the dynamic pathway of the ligand from the bulk solvent to the heme pocket, where it reacts with the heme $\mathrm{Fe}(\mathrm{II})$ atom (i.e. step 2 of Scheme 5, characterized by $k_{+2}$ and $k_{-2}$ ).

Values of $k_{\text {on }}, k_{\max }$ and $K_{\text {pre }}$ were obtained according to Eqn (9) [22]:

$$
k_{\mathrm{obs}}=k_{\max } \times[\text { cyanide }] /\left(K_{\mathrm{pre}}+[\text { cyanide }]\right)
$$

Under conditions where the cyanide concentration $\leq 10 \times K_{\text {pre }}$, Eqn (9) approximates to Eqn (10) [22]:

$$
k_{\mathrm{obs}}=k_{\mathrm{on}} \times[\text { cyanide }]
$$

\section{Thermodynamics of cyanide binding to $M t$-trHbN(II), Mt-trHbO(II), and $C_{j}$-trHbP(II)}

The thermodynamics of cyanide binding to $M t$-trHbN(II), $M t$-trHbO(II) and $C j$-trHbP(II) were determined by adding a cyanide-buffered solution (from $2.5 \times 10^{-7} \mathrm{M}$ to $1.3 \mathrm{M}$ ) to a protein-buffered solution $([M t-\operatorname{trHbN}(\mathrm{II})]=$ $2.9 \times 10^{-6} \mathrm{M}, \quad[M t$-trHbO(II) $]=2.3 \times 10^{-6} \mathrm{M}, \quad$ and $[C j$-trHbP(II) $\left.]=3.5 \times 10^{-6} \mathrm{M}\right)$. The reaction was followed spectrophotometrically between $350 \mathrm{~nm}$ and $460 \mathrm{~nm}$ (see Table 2). Absorbance spectra were recorded after achieving the equilibrium (the equilibration time ranged between $10 \mathrm{~min}$ and $12 \mathrm{~h}$ ). No gaseous phase was present.

The dependence of the molar fraction of cyanide-bound $\operatorname{trHb}(\mathrm{II})$ (i.e. $\alpha$ ) on cyanide concentration was analyzed according to the minimum reaction mechanism shown in Scheme 6 [21]:

$$
\operatorname{trHb}(\mathrm{II})+\text { cyanide } \underset{k_{\text {off }}}{\stackrel{k_{\text {on }}}{\leftrightarrow}} \operatorname{trHb}(\mathrm{II}) \text {-cyanide }
$$

(Scheme 6) 
Values of the dissociation equilibrium constant for cyanide binding to $M t$-trHbN(II), $M t$-trHbO(II) and $C j$-trHbP(II) $\left(K=k_{\text {off }} / k_{\text {on }}\right)$ were calculated according to Eqn (11) [23]:

$$
\begin{aligned}
\alpha= & (-([\text { cyanide }]+K+[\operatorname{trHb}(\mathrm{II})])+\sqrt{ }(([\text { cyanide }]+K \\
+ & {\left.\left.[\operatorname{trHb}(\mathrm{II})])^{2}-4 \times[\text { cyanide }] \times[\operatorname{trHb}(\mathrm{II})]\right)\right) / } \\
& (2 \times[\operatorname{trHb}(\mathrm{II})])
\end{aligned}
$$

\section{Data analysis}

Data analysis was performed with the program MATLAB 7.0 (MathWorks Inc., South Natick, MA, USA). All data (obtained at $\mathrm{pH} 7.0,1.0 \times 10^{-1} \mathrm{M}$ phosphate buffer, and $20.0^{\circ} \mathrm{C}$ ) were determined at least in quadruplicate.

\section{Acknowledgements}

Professor Martino Bolognesi is grateful to CIMAINA (Milano, Italy) for continuous support. Part of this study was supported by grants from the Natural Sciences and Engineering Research Council of Canada (grant 46306-01, 2005-2010) to M. Guertin, the National Institute of Health of the USA (grant 1-R01AI052258, 2004-2007) to M. Guertin, the Ministry for University and Scientific Research of Italy (FIRB Project 'Biologia Strutturale', contract RBLA03B3KC) to M. Bolognesi, the Ministry of Health of Italy (INMIIRCCS 'Lazzaro Spallanzani', Roma, Italy, Ricerca corrente 2006) to P. Ascenzi, and University 'Roma Tre' (Roma, Italy, CLAR-2006) to P. Ascenzi.

\section{References}

1 Bolognesi M, Bordo D, Rizzi M, Tarricone C \& Ascenzi P (1997) Nonvertebrate hemoglobins: structural bases for reactivity. Prog Biophys Mol Biol 68, 29-68.

2 Poole RK \& Hughes MN (2000) New functions for the ancient globin family: bacterial responses to nitric oxide and nitrosative stress. Mol Microbiol 36, 775-783.

3 Wittenberg JB, Bolognesi M, Wittenberg BA \& Guertin M (2002) Truncated hemoglobins: a new family of hemoglobins widely distributed in bacteria, unicellular eukaryotes, and plants. J Biol Chem 277, 871-874.

4 Wu G, Wainwright LM \& Poole RK (2003) Microbial globins. Adv Microb Physiol 47, 255-310.

5 Frey AD \& Kallio PT (2003) Bacterial hemoglobins and flavohemoglobins: versatile proteins and their impact on microbiology and biotechnology. FEMS Microbiol Rev 27, 525-545.

6 Egawa T \& Yeh SR (2005) Structural and functional properties of hemoglobins from unicellular organisms as revealed by resonance Raman spectroscopy. J Inorg Biochem 99, 72-96.

7 Vinogradov SN, Hoogewijs D, Bailly X, ArredondoPeter R, Gough J, Dewilde S, Moens L \& Vanfleteren JR (2006) A phylogenomic profile of globins. $B M C$ Evol Biol 6, 31.

8 Vuletich DA \& Lecomte JT (2006) A phylogenetic and structural analysis of truncated hemoglobins. $J \mathrm{Mol}$ Evol 62, 196-210.

9 Ascenzi P, Bolognesi M, Milani M, Guertin M \& Visca P (2007) Mycobacterial truncated hemoglobins: from genes to functions. Gene 398, 42-51.

10 Altekruse SF, Stern NJ, Fields PI \& Swerdlow DL (1999) Campylobacter jejuni - an emerging foodborne pathogen. Emerg Infect Dis 5, 28-35.

11 Moore JE, Corcoran D, Dooley JS, Fanning S, Lucey B, Matsuda M, McDowell DA, Megraud F, Millar BC, O’Mahony R et al. (2005) Campylobacter. Vet Res 36, 351-382.

12 Young KT, Davis LM \& DiRita VJ (2007) Campylobacter jejuni: molecular biology and pathogenesis. Nat Rev Microbiol 5, 665-679.

13 Elvers KT, Wu G, Gilberthorpe NJ, Poole RK \& Park SF (2004) Role of an inducible single-domain hemoglobin in mediating resistance to nitric oxide and nitrosative stress in Campylobacter jejuni and Campylobacter coli. J Bacteriol 186, 5332-5341.

14 Lu C, Mukai M, Lin Y, Wu G, Poole RK \& Yeh SR (2007) Structural and functional properties of a single domain hemoglobin from the food-borne pathogen Campylobacter jejuni. J Biol Chem 282, 25917-25928.

15 Wainwright LM, Elvers KT, Park SF \& Poole RK (2005) A truncated haemoglobin implicated in oxygen metabolism by the microaerophilic food-borne pathogen Campylobacter jejuni. Microbiology 151, 4079-4091.

16 Nardini M, Pesce A, Labarre M, Richard C, Bolli A, Ascenzi P, Guertin M \& Bolognesi M (2006) Structural determinants in the group III truncated hemoglobin from Campylobacter jejuni. J Biol Chem 281, 3780337812 .

17 Lu C, Egawa T, Wainwright LM, Poole RK \& Yeh SR (2007) Structural and functional properties of a truncated hemoglobin from a food-borne pathogen Campylobacter jejuni. J Biol Chem 282, 13627-13636.

18 Milani M, Ouellet Y, Ouellet H, Guertin M, Boffi A, Antonini G, Bocedi A, Mattu M, Bolognesi M \& Ascenzi P (2004) Cyanide binding to truncated hemoglobins: a crystallographic and kinetic study. Biochemistry 43, 5213-5221.

19 Hughes MA, Sharif AL, Dunn MA \& Oxtoby E (1988) The molecular biology of cyanogenesis. Ciba Found Symp 140, 111-130.

20 Mintorovitch J, van Pelt D \& Satterlee JD (1989) Kinetic study of the slow cyanide binding to Glycera 
dibranchiata monomer hemoglobin components III and IV. Biochemistry 28, 6099-6104.

21 Antonini E \& Brunori M (1971) Hemoglobin and myoglobin in their reactions with ligands. North Holland Publishing Co., Amsterdam.

22 Antonini E, Ascenzi P, Menegatti E \& Guarneri M (1983) Multiple intermediates in the reaction of bovine $\beta$-trypsin with bovine pancreatic trypsin inhibitor (Kunitz). Biopolymers 22, 363-375.

23 Claro E (2006) Analyzing ligand depletion in a saturation equilibrium binding experiment. Biochem $\mathrm{Mol}$ Biol Educ 34, 428-431.

24 Ellis WD \& Dunford HB (1968) The kinetics of cyanide and fluoride binding by ferric horseradish peroxidase. Biochemistry 7, 2054-2062.

25 Gibson QH, Parkhurst LJ \& Geraci G (1969) The reaction of methemoglobin with some ligands. $J$ Biol Chem 244, 4668-4676.

26 Erman JE (1974) Kinetic and equilibrium studies of cyanide binding by cytochrome $c$ peroxidase. Biochemistry 13, 39-44.

27 Cox RP \& Hollaway MR (1977) The reduction by dithionite of $\mathrm{Fe}(\mathrm{III})$ myoglobin derivatives with different ligands attached to the iron atom. A study by rapid-wavelength-scanning stopped-flow spectrophotometry. Eur J Biochem 74, 575-587.

28 Job D, Zeba B, Puppo A \& Rigaud J (1980) Kinetic studies of the reaction of ferric soybean leghemoglobins with hydrogen peroxide, cyanide and nicotinic acid. Eur $J$ Biochem 107, 491-500.

29 Nardini M, Tarricone C, Rizzi M, Lania A, Desideri A, De Sanctis G, Coletta M, Petruzzelli R, Ascenzi P, Coda A et al. (1995) Reptile heme protein structure: $\mathrm{X}$-ray crystallographic study of the aquo-met and cyano-met derivatives of the loggerhead sea turtle (Caretta caretta) myoglobin at $2.0 \AA$ resolution. $J \mathrm{Mol}$ Biol 247, 459-465.

30 Boffi A, Ilari A, Spagnuolo C \& Chiancone E (1996) Unusual affinity of cyanide for ferrous and ferric Scapharca inaequivalvis homodimeric hemoglobin. Equilibria and kinetics of the reaction. Biochemistry 35, 80688074.

31 Bolognesi M, Boffi A, Coletta M, Mozzarelli A, Pesce A, Tarricone C \& Ascenzi P (1999) Anticooperative ligand binding properties of recombinant ferric Vitreoscilla homodimeric hemoglobin: a thermodynamic, kinetic and X-ray crystallographic study. J Mol Biol 291, 637650 .

32 Bolognesi M, Rosano C, Losso R, Borassi A, Rizzi M, Wittenberg JB, Boffi A \& Ascenzi P (1999) Cyanide binding to Lucina pectinata hemoglobin I and to sperm whale myoglobin: an X-ray crystallographic study. Biophys J 77, 1093-1099.

33 Stitt F \& Coryell CD (1939) The magnetic study of the equilibrium between ferrohemoglobin, cyanide ion, and cyanide ferrohemoglobin. J Am Chem Soc 61, 1263 1266.

34 Keilin D \& Hartree EF (1955) Cyanide compounds of ferroperoxidase and myoglobin and their reversible photodissociation. Biochem J 61, 153-171.

35 Phelps CF, Antonini E \& Brunori M (1971) The binding of cyanide to ferroperoxidase. Biochem $J$ 122, 79-87.

36 Olivas E, De Waal DJ \& Wilkins RG (1977) Reduction of metmyoglobin derivatives by dithionite ion. $J$ Biol Chem 252, 4038-4042.

37 Bellelli A, Antonini G, Brunori M, Springer BA \& Sligar SG (1990) Transient spectroscopy of the reaction of cyanide with ferrous myoglobin. $J$ Biol Chem $\mathbf{2 6 5}$, 18898-18901.

38 Brunori M, Antonini G, Castagnola M \& Bellelli A (1992) Cooperative cyanide dissociation from ferrous hemoglobin. J Biol Chem 267, 2258-2263.

39 Antonini G, Bellelli A, Concetti A, Falcioni G \& Brunori M (1994) Cyanide dissociation from the hemoglobin of Parascaris equorum. Biochim Biophys Acta 1025, 252-257.

40 Antonini G, Bellelli A, Brunori M \& Falcioni G (1996) Kinetic and spectroscopic properties of the cyanide complexes of ferrous haemoglobins I and IV from trout blood. Biochem J 314, 533-540.

41 Boffi A, Chiancone E, Takahashi S \& Rousseau DL (1997) Stereochemistry of the Fe(II)- and Fe(III)-cyanide complexes of the homodimeric Scapharca inaequivalvis hemoglobin. A resonance Raman and FTIR study. Biochemistry 36, 4505-4509.

42 Boffi A, Chiancone E, Peterson ES, Wang J, Rousseau DL \& Friedman JM (1997) Dynamics of cyanide binding to ferrous Scapharca inaequivalvis homodimeric hemoglobin. Biochemistry 36, 4510-4514.

43 Wittenberg JB, Noble RW, Wittenberg BA, Antonini E, Brunori M \& Wyman J (1967) Studies on the equilibria and kinetics of the reactions of peroxidase with ligands: II. The reaction of ferroperoxidase with oxygen. $J$ Biol Chem 242, 626-634.

44 Kertesz D, Antonini E, Brunori M, Wyman J \& Zito R (1965) Studies on the equilibria and kinetics of the reactions of peroxidases with ligands. I. The reaction of ferroperoxidases with carbon monoxide. Biochemistry 4 , 2672-2676.

45 Coletta M, Ascoli F, Brunori M \& Traylor TG (1986) $\mathrm{pH}$ dependence of carbon monoxide binding to ferrous horse radish peroxidase. J Biol Chem 261, 9811-9814.

46 Brunori M, Coletta M, Ascenzi P \& Bolognesi M (1989) Kinetic control of ligand binding processes in hemoproteins. J Mol Liq 42, 175-193.

47 Springer BA, Sligar SG, Olson JS \& Phillips JN (1994) Mechanisms of ligand recognition in myoglobin. Chem Rev 94, 699-714.

48 Brancaccio A, Cutruzzolà F, Travaglini Allocatelli C, Brunori M, Smerdon SJ, Wilkinson AJ, Dou Y, 
Keenan D, Ikeda-Saito M, Brantley RE Jr et al. (1994) Structural factors governing azide and cyanide binding to mammalian metmyoglobins. J Biol Chem 269, 13843-13853.

49 Milani M, Pesce A, Ouellet Y, Ascenzi P, Guertin M \& Bolognesi M (2001) Mycobacterium tuberculosis hemoglobin $\mathrm{N}$ displays a protein tunnel suited for $\mathrm{O}_{2}$ diffusion to the heme. EMBO J 20, 3902-3909.

50 Milani M, Pesce A, Ouellet Y, Dewilde S, Friedman J, Ascenzi P, Guertin M \& Bolognesi M (2004) Hemeligand tunneling in group I truncated hemoglobins. $J$ Biol Chem 279, 21520-21525.

51 Milani M, Savard PY, Ouellet H, Ascenzi P, Guertin M \& Bolognesi M (2003) A TyrCD1/TrpG8 hydrogen bond network and a TyrB10TyrCD1 covalent link shape the heme distal site of Mycobacterium tuberculosis hemoglobin O. Proc Natl Acad Sci USA 100, 5766-5771.
52 Jackson RJ, Elvers KT, Lee LJ, Gidley MD, Wainwright LM, Lightfoot J, Park SF \& Poole RK (2007) Oxygen reactivity of both respiratory oxidases in Campylobacter jejuni: the $c y d A B$ genes encode a cyanide-resistant, low-affinity oxidase that is not of the cytochrome $b d$ type. J Bacteriol 189, 1604-1615.

53 Couture M, Yeh S, Wittenberg BA, Wittenberg JB, Ouellet Y, Rousseau DL \& Guertin M (1999) A cooperative oxygen-binding hemoglobin from Mycobacterium tuberculosis. Proc Natl Acad Sci USA 96, 11223-11228.

54 Mukai M, Savard PY, Ouellet H, Guertin M \& Yeh SR (2002) Unique ligand-protein interactions in a new truncated hemoglobin from Mycobacterium tuberculosis. Biochemistry 41, 3897-3905.

55 Kraulis PJ (1991) Molscript: a program to produce both detailed and schematic plots of protein structures. J Appl Crystallogr 24, 946-950. 